\title{
REGULATING SYSTEMIC RISK THROUGH TRANSPARENCY: TRADEOFFS IN MAKING DATA PUBLIC
}

\author{
Augustin Landier \\ David Thesmar \\ Working Paper 17664 \\ http://www.nber.org/papers/w17664
NATIONAL BUREAU OF ECONOMIC RESEARCH
1050 Massachusetts Avenue
Cambridge, MA 02138 \\ December 2011
}

The views expressed herein are those of the authors and do not necessarily reflect the views of the National Bureau of Economic Research.

NBER working papers are circulated for discussion and comment purposes. They have not been peerreviewed or been subject to the review by the NBER Board of Directors that accompanies official NBER publications.

(C) 2011 by Augustin Landier and David Thesmar. All rights reserved. Short sections of text, not to exceed two paragraphs, may be quoted without explicit permission provided that full credit, including (C) notice, is given to the source. 
Regulating Systemic Risk through Transparency: Tradeoffs in Making Data Public Augustin Landier and David Thesmar

NBER Working Paper No. 17664

December 2011

JEL No. D82,D83,H41

\title{
ABSTRACT
}

Public or partial disclosure of financial data is a key element in the design of a new regulatory environment. We study the costs and benefits of higher public access to financial data and analyze qualitatively how frequency, disclosure lag and granularity of such open data can be chosen to maximize welfare, depending on the relative magnitude of economic frictions. We lay out a simple framework to choose optimal transparency of financial data.

\author{
Augustin Landier \\ the Toulouse School of Economics \\ 21 Allée de Brienne \\ 31000 Toulouse, FRANCE \\ augustin.landier@tse-fr.eu \\ David Thesmar \\ HEC Paris \\ 1 rue de la libération \\ 78351 Jouy-en-Josas cedex \\ France \\ thesmar@hec.fr
}




\title{
Regulating Systemic Risk through Transparency: Tradeoffs in Making Data Public
}

\author{
Augustin Landier (TSE) and David Thesmar (HEC) ${ }^{1}$
}

\begin{abstract}
Public or partial disclosure of financial data is a key element in the design of a new regulatory environment. We study the costs and benefits of higher public access to financial data and analyze qualitatively how frequency, disclosure lag and granularity of such open data can be chosen to maximize welfare, depending on the relative magnitude of economic frictions. We lay out a simple framework to choose optimal transparency of financial data.
\end{abstract}

According to many observers, the financial crisis is a product of the lack of transparency of the financial system. In a recent speech, Fed chairman Ben Bernanke acknowledged that opaqueness was a "structural weakness in the shadow banking system" and an important element in the narrative of the crisis. ${ }^{2}$ Examples of such opaqueness are OTC markets such as the CDS market, for which there is little detailed data about holdings, prices and collateral posted. This made it difficult for the regulator to understand the web of counterparty exposures and have its independent assessment of the overall resilience of the system.

Besides what was available to the regulator, public disclosure of financial information was probably insufficient. For instance, the lack of micro-data on the content of securitized products made it difficult for investor to price risk correctly. Market participants trading securitized products such as collateralized debt obligations (CDOs) and collateralized mortgage obligations (CMOs) were relying on imprecise, and sometimes flawed, ratings (Benmelech and Dlugoszb (2008)). Beyond pricing, public availability of data is argued to enhance the role that researchers outside the government (from universities, think-tanks or other private institutions) can play in assisting, and to some extent monitor, regulators. ${ }^{3}$

This article is about the optimal degree of public disclosure of financial data. Theoretically, however, increasing transparency may reduce welfare as well as increase it. For instance, Dang, Gorton and Holmström (2010) argue that common ignorance of market participants about the precise nature of some assets might be a desired feature rather than a bug of the financial system. Such assets might deliberately be constructed as opaque to remain information insensitive. Releasing more information in the public domain might thus be welfare decreasing. Other voices, notably from the private sector, warn that extreme

\footnotetext{
${ }^{1}$ We thank Markus Brunnermeier, Arvind Krishnamurthy, Luigi Zingales, and other participants to the NBER Systemic Risk meeting in Chicago, May 2011.

${ }^{2}$ Speech given at the 2010 Squam Lake conference. http://www.federalreserve.gov/newsevents/speech/bernanke20100616a.htm

${ }^{3}$ Mary Graham, 2002, "Democracy by Disclosure", Brookings Institution Press, Washington DC
} 
transparency might be detrimental to incentives of financial agents to produce information and to innovate.

In this paper, we develop a framework to understand the costs and benefits of public disclosure of financial data. We believe such a framework can help regulators to determine the format under which data should be publicly accessible, as a function of the type of information under consideration. In our framework, the welfare impact of public access to data depends on three dimensions: (1) the frequency of data collection, (2) the time-lag of their public release and (3) their level of granularity / anonymity. Granularity and anonymity are linked as less granular (more aggregated) data make it easier to protect anonymity.

In doing so, our framework addresses the following questions:

- At what frequency should data be collected and made available?

- How long should the regulator wait before releasing the data?

- At what level of detail (granularity) should information be released? If the public information is detailed, should it be made anonymous?

Frequency, lag and granularity are important choice variables for regulators who wish to publicly disclose data; yet, there is no systematic doctrine about their optimal level. To give examples, some data are currently publicly available at very fine levels of granularity (13Fs filings provide at the institution level an exhaustive position-by-position view of individual long equity holdings at a quarterly frequency). By contrast some other data are available only at an aggregated level (e.g. new lending by banks, or bank cross-country exposures). But these choices owe more to history and political compromises than to a systematic cost and benefit analysis.

In the first section of the paper, we review the various economic costs associated to public data release and review the corresponding academic literature. In the second section, we present several dimensions of data that can be optimized to mitigate each of these costs. Last, we review the positive impact that might be expected from public access to financial data and develop a framework to manage on a case-by-case basis the cost-benefit trade-off, notably through the choice of disclosure lags and granularity.

\section{The potential costs of transparency: a review of economic forces at stakes}

There is a basic intuitive economic reason why more information is a priori better than less: Individual decisions are closer to being privately optimal when agents have more accurate information. Since, in a frictionless economy, private and social efficiency do not differ, it follows that full public disclosure of information is always desirable from a welfare perspective if we abstract from frictions. However, this prediction does not hold any more in the presence of economic frictions. In this section, we review the various kinds of frictions that can create a welfare cost to the public release of financial information. 
A direct cost of transparency is simply that of producing, storing, certifying and disseminating information. For a long time, such costs have been an important margin in deciding the optimal level of public disclosure. Today, while these costs might not be trivial, they have been enormously diminished (the cost of saving one bit of information on hard disk storage space has decreased by almost $1.5 \mathrm{M}$ times since 1980 ).

Moreover, much financial information that one might be inclined to disclose consists in information that financial firms already produce for internal use. For instance, disaggregated data on holdings and liabilities is a necessary ingredient of sound risk-management by financial institutions. The need to transmit them to regulators and/or to the public might thus not be a high additional cost to companies. In what follows, we will focus on other costs than these simple material costs of producing and managing information.

\section{b. Secrecy might be vital to some activities in finance}

A second line of arguments against imposing higher transparency is that it might discourage the production of information by financial intermediaries and consequently decrease market efficiency. To have incentives to produce information, economic agents need to be able to use it to make profits, which might require a temporary monopoly power on that information. For instance, after paying the cost to identify an arbitrage opportunity, a hedge fund manager might need time to exploit the opportunity before it gets revealed to the public. If positions are disclosed quickly, the fund might not have had time to enter positions at a sufficient scale to recoup the initial cost.

Thus, by decreasing rents of arbitrageurs, transparency might, according to that view, reduce market efficiency (this is related to the Grossman-Stiglitz paradox). Opacity in finance might be useful in protecting rents from information production, akin to trade secrets or patents in other high-tech industries. One empirical example where this property right argument has some empirical bite, however, seems to be that of analyst's coverage. Gomes, Gorton and Madureira (2004) study the consequences of the adoption of Regulation Fair Disclosure ("Reg FD") by the U.S. Securities and Exchange Commission in October 2000, a regulation that prevents firms from selectively disclosing information to some market participants (typically a few selected analysts), but not others. They find that this regulation led to a loss of analyst coverage for small firms and to a higher cost of capital. Their interpretation is that by eliminating the temporary monopoly power of some analysts on information, the regulation discouraged them to work on small firms.

In finance, the property right argument is hard to reconcile with recent trends in the cost of information accumulation and evolution of rents in the sector. ${ }^{4}$ There is evidence that wages and profits in the financial sector have risen to abnormally high levels (see e.g. Philippon and Reshef, 2008). At the same time, the cost of gathering, storing and processing information has decreased massively. Hence, for the current level of financial rents to be optimal, we need information acquisition to have become extremely (socially) valuable in today's economies.

c. Transparency may generate instability...

\footnotetext{
${ }^{4}$ Moreover, the empirical evidence from non-financial industries also indicates that strong intellectual property protection often decreases innovation speed (see e.g. Williams (2010) or Boldrin and Levine (2007)).
} 
Various academic theories provide models where the disclosure of more public information can generate financial instability, increased volatility and/or reduced liquidity. We provide in this subsection a categorization of these theories.

\section{i. $\quad$...when it creates asymmetric information,}

Several papers argue that when complex information is released to the public, only the most sophisticated agents are able to process it. Thus, increased transparency can generate asymmetric information among agents, which in turn can make markets less liquid or even collapse à la Akerlof (1970). The more complex the information to be released is, the stronger this effect. For instance, Pagano and Volpin (2010) have a model along this line of research where they emphasize the view that transparency enhances liquidity only if market participants are equally skilled at information processing. In their model, some investors have limited ability to process information. Thus, releasing more public information can increase adverse selection in the market and reduce liquidity. Similarly, Dang, Gorton, and Holmström, 2010, also develop a model where common ignorance facilitates trading. More transparency can lead to the inefficient emergence of adverse. Their paper suggests that certain types of market securities, such as securitized products, are designed to be information-insensitive and thus deliberately constructed to be opaque. Markets for such securities can function better if all agents are kept uninformed about details so that no one suspects other agents of being trading with superior information. Holmström (2008) notes that when De Beers sells wholesale diamonds, the stones are placed in opaque packets that buyers are forbidden to explore, to avoid the occurrence of a lemon's problem.

Empirical evidence looking at the introduction of a fundamental change of the US bond market tends however to find positive liquidity effects of transparency: After July 2002, the Transaction Reporting and Compliance Engine (TRACE) requires bond dealers to report all trades in publicly-issued corporate bonds. The National Association of Security Dealers, makes the transaction data accessible freely to the public. Several studies find that the cost of trading corporate bonds has decreased following the increase in transparency (see Goldstein et al. (2007), Edwards et al. (2008), Bessembinder et al. (2006)).

\section{ii....when it creates coordination failures,}

The 'global games' literature has examined the impact of public information in coordination games where agents have both private and public information. Morris and Shin (2002) shows that the provision of more precise public information can be detrimental to welfare. The reason is that agents (rationally) overreact to public information compared to the social optimum, and hence noise in public signals can cause social inefficiencies. An increase in the precision of public information may have the perverse effect of increasing aggregate volatility, as economic activity becomes more sensitive to common noise. The reason is that private signals are not used in a socially optimal manner in the presence of strong public signals.

In the same vein, Amador and Weill (2010) show that the availability of more public information can limit the incorporation of private signals into prices and thus be welfare decreasing (see also Duffie-Malamud-Manso, 2010). In the presence of multiple equilibria, public information can also lead to the selection of a bad equilibrium. 
Morris and Shin (2007) have a model where coarser information has greater chance to being understood by all market participants than granular information and thus leads to better coordination among agents. They emphasize a tradeoff between the quantity of information and its shared nature. If coordination requires a common understanding of information, it is possible for increased transparency to be welfare decreasing. This is because some market observers (possibly a small minority) fail to understand the information.

\section{iii. $\quad$...when it facilitates predatory trading}

Investors in financial distress can be forced to unwind quickly their positions. When the holdings of such investors are known by other traders, such liquidations can give rise to predatory trading: Informed traders anticipate the fire-sale and initially trade in the same direction as the distressed institution, which amplifies the shock to asset prices. Brunnermeier and Pedersen (2007) provide a continuous time model that solves for the price trajectory in the presence of fire sales and quantify the amplifying impact of predatory trading on price swings. They emphasize the risk of systemic destabilization induced by such predatory trading and use as a motivating example the alleged trading against Long Term Capital Management's (LTCM's) positions in the fall of 1998 which led to the concern that LTCM's financial difficulties might destabilize the financial system as a whole. This kind of destabilizing speculation is facilitated when both the individual shocks leading to fire-sales (such as performance or outflows) and the individual holdings of investors are public information.

Empirically, Coval and Stafford (2007) study the price impact of mutual funds outflows. They emphasize the fact that, public disclosure of funds holdings makes future flow-driven transactions predictable. This creates an incentive to front-run the anticipated fire-sales of distressed mutual funds that are experiencing large capital outflows. Such front-running strategies are shown to be profitable. They decrease the price at which these distressed funds are able to liquidate positions. Looking at hedge fund holding data, Greenwood and Thesmar (2011) find little evidence of such front-running by hedge funds. On average, hedge fund trading is not correlated with mutual fund fire-sales. For some stocks, this correlation is positive (front-running), but for others, this correlation is negative (liquidity provision).

iv. $\quad$...when it generates perverse incentives to offset regulation.

Higher transparency imposed to institutions can generate large offsetting effects. Faced with higher disclosure requirements, financial institutions might strategically attempt to find ways to manipulate disclosures in a self-serving manner. The economic forces behind such offsetting effects are well known: agents try to strategically manipulate to their advantage the signals that are used by regulators or principals to evaluate them (Holmström 1999, Holmström and Milgrom 1991). Such inefficient "signal jamming” can lead to substantial distortions.

Directly related to the offsetting effects of disclosure requirements, a large literature studies how publically traded companies engage into earnings smoothing and various accounting manipulations to optimize market reactions to their corporate financial reporting. Bergstresser and Philippon (2004), show that discretionary accruals are used strategically by CEOs to 
manipulate reported earnings. Graham et al (2005) find that $78 \%$ of a representative sample of top executives admits to "sacrificing long-term value to smooth earnings". In the same vein, Chevalier and Ellison (1997) show that mutual fund managers who are performing well relative to the market gamble to make year-end lists of "top performers": this is again an example of "jamming” of publically observed signals.

Such offsetting effects due to regulatory constraints have actually been at paly in the current crisis: The shadow banking system was partly developed as a way to bypass regulatory constraints, notably capital requirements. Asset-backed commercial paper conduits became an increasingly large source of funding for commercial banks, reaching US\$1.4 trillion in June 2007 (see Acharya et al (2009) and Brunnermeier (2009)).

\section{The three determinants of the costs and benefits to publicly disclose financial data}

The costs of public disclosure listed above are potentially affected by three parameters. These parameters are all choice variables of the regulator who is in charge of disseminating the information. In this Section, we describe these parameters and their effect on the costs of transparency. We defer the discussion on their impact on benefits of disclosure to the next Section.

The three determinants of the costs and benefit of transparency are:

- Granularity: There are two levels of granularity, that of the reporting entity, and that of the reported positions. Regarding positions, data can be at the individual position level (e.g. quantity of common stocks of company $i$ held) or at a more aggregate level (e.g. quantity of stocks in industry $i$ held). Similarly, reports can give holdings at the individual legal entity level or at a more aggregate level. For instance $13 \mathrm{~F}$ reports provide fully granular data on long equity holdings: Each reporting entity has to file its positions in each individual company. By contrast, BIS reports are more aggregated, as they give the consolidated exposure of all the banks of country $i$ to any given foreign country $j$. Note that granularity and anonymity are to be determined jointly: to make data anonymous (i.e. such that the reporting entity cannot be identified by the user), it is usually needed to pick an appropriate level of aggregation, otherwise, users might infer from the data what institution/individual is reporting. E.g. the ranking of bank by asset size is known, and thus data that would provide total balance sheet size information would be de-facto non-anonymous.

- Frequency: Data can be reported at various frequencies. When frequencies are too low (e.g. annual or quarterly), a risk exists that institutions engage in window dressing by changing holdings right before they have to report. To avoid such gaming of the system without incurring the inconvenience of high frequency reporting, institutions could be asked to provide average numbers over a given period as advised in the Geneva Report.

- Lag of Disclosure: Data regarding holdings at date t can be reported at time t' and made available at a later date t' $>t$ ' to the public. The public disclosure lag is t' $-t$ and 
the reporting lag is t'-t. For instance, form $13 \mathrm{~F}$ is required to be filed to the SEC by large institutional owners within 45 days of the end of a calendar quarter and is made available immediately on the SEC's website, i.e. $\mathrm{t}$ '-t=t''-t=45days.

Let us now turn to the impact of these three determinants on the costs of transparency. Lag of disclosure and granularity are key margins to reduce these costs. The revelation of "cold" information won't induce lemons problems, coordination failures, nor a substantial loss in trading profitability. A delay of six months to one year seems reasonable in most cases. Zingales (2010) suggests delays of one- to two-year before full disclosure of individual data in private equity and hedge funds. His argument is the following: "This delay will eliminate any competitive concern, since the half-life of a portfolio strategy is very short on Wall Street (Grinold and Kahn [2000] estimate it as 1.2 years), while still providing the benefit of a serious statistical analysis of this market, which will improve allocation. ». Still, some agents might argue that key proprietary processes might be reverse-engineered by observing data and could be detrimental to profitability. Facing such arguments, the regulator has to estimate whether this is a credible threat to the business; if so, the solution is to reveal data at more aggregate levels, thus limiting the possibility of reverse-engineering. However, less granular information on holdings might be easier to manipulate than lists of individual holdings (granular information).

\section{The potential gains from public disclosure}

We now turn to the potential welfare gains from public access to financial data. In each case, we will review the extent to which the benefits depend on frequency, lags and granularity. A frequent question in financial economics is why firms do not set the right level of disclosure by themselves (Leuz and Wysocki, 2008). After all, if information is useful to buyers of securities, they should be willing to pay a higher price to be informed. In the case of systemic risk, the reason for the under-provision of public information by private actors is simple: firms do not internalize the impact that their level of disclosure can have on the stability of the financial system via the knowledge of other participants (including the regulator). There is thus a motive for compulsory disclosure of information.

\section{a. "crowd-sourcing" and the value of "free-range" research}

One option available to regulators is to behave as gate-keepers regarding the data and provide access to them only to selected teams of researchers who present a project that is considered valuable for regulatory purpose. However, there are several reasons that might make such restrictive access suboptimal.

First, many research projects are not well defined at an early stage and it is often only after thorough data exploration that researchers are able to spot new relevant questions or anomalies worth to be investigated. If data are not publically accessible, such exploration is less likely to take place. Second, any gate-keeping institution is likely to become excessively protective about the use of data and favor internal or more connected researchers. It is difficult to conceive a governance mechanism that would surely defeat the emergence of such monopolistic behavior.

Data availability directly feeds research intensity: Kevin Murphy shows that the average number of CEO pay papers produced per year has doubled after the Executive compensation data for large US companies (EXECUCOMP) became available in 1992. In several instances, such research has had direct regulatory impact. An instance of influential forensic analysis by 
academics in finance is the work of Heron and Lie (2007, 2009). Using public Executive Compensation data, they uncovered a widespread practice of backdating of option grant dates among US executives. They estimate that $18.9 \%$ of option grants of US top executives during the period 1996-2005 were backdated. Their study led to a large SEC inquiry into this illegal practice. The impact of researchers using their free access to the data to identify new topics or anomalies worth being investigated by regulators is historically validated by several other examples. Notably, numerous academic studies have investigated the behavior of mutual funds, taking advantage of public holdings and performance data provided by the SEC. For instance, Carhart, Kaniel, Musto, and Reed (2002) document that the prices of stocks owned by mutual funds exhibit positive abnormal returns at the end of the quarter. Duong, and Meschke (2008) find no evidence for such manipulation by mutual funds post 2000 suggesting that the increased scrutiny following the publication of the results has led to a decrease in manipulation of that sort. 13F filings have widely been used in research to study the potentially destabilizing role of institutional investors in financial markets. Brunnermeier and Nagel (2004) explore the behavior of hedge funds during the Internet bubble and show that they were long technology stocks during the most part of the bubble, thus playing a destabilizing role. Insider trading data are also largely exploited by researchers. It is easy to imagine how much more could be done if wider data were available. For instance the fact that short positions are not available in 13Fs has limited the scope of research on the market impact of hedge funds.

The internal politics of bureaucratic organizations might create a climate favorable to statusquo bias and reluctance to ask disturbing questions. An open-source approach to the use of data might mitigate these biases, by letting researchers from various horizons free to ask questions that might seem a priori unwarranted. The "wisdom of crowds" effect stemming from a large pool of external researchers that are not filtered by (or affiliated to) the regulator can hardly be replicated in-house. Small groups of experts tend to be prone to consensus and are less likely to ask the disturbing questions. Researchers internal to regulatory agencies might become too confident in the system and miss the build-up of excessive risk taking. New forms of risks might emerge from unpredictable parts of asset classes that specialized researchers might dismiss as innocuous out of habit. Such cognitive and organizational "groupthink" effects and their causes are explored in Benabou (2010) (see also Janis (1982)). ${ }^{5}$

For the wisdom of crowd effect to take place, granular data might be important because categories used by regulators to aggregate data can slowly become obsolete. In some cases, regulators might even deliberately provide hard to use aggregates to preserve their monopoly in the use of the data. New sources of risks are likely to come from unexpected parts of the system, or innovations such as "game-changing" products that do not fit existing categories. To address such changing environment, access to granular data is key. Cheng, Kirilenko and Xiong (2011) show how using granular (but not public) data from the CFTC, the impact of indexed traders on commodity prices can be inferred. Their analysis cannot be undertaken using the public aggregate data reported by the CFTC.

Disclosure lags (as long as they are not too extreme) will not diminish the interest of researchers for data, nor the relevance of their contributions: based on 2003-2004 data, researchers may have produced highly relevant research for taking regulatory decisions in 2007-2008.

\footnotetext{
${ }^{5}$ The wisdom of crowds effect we are referring to is by no means akin to a form of "self-regulation”. Quite to the contrary, contributions from unaffiliated researchers can enrich and complement the work of regulators and help them reaching efficient decisions.
} 


\section{b. avoiding regulatory capture}

Regulatory capture occurs when the regulated industry manages to bias the regulator's decisions in its favor (Stigler, 1971). ${ }^{6}$ Incentives of regulators might be improved if internal data are made available to the large public ex-post, so that researchers and other outside experts can externally monitor regulatory decisions. Moreover, even absent incentive problems from regulators (i.e. even if they turned out to automatically make socially optimal choices), the possibility to judge ex-post that their decisions were ex-ante justified based on their information set is important: it reinforces the legitimacy of their choices and the confidence of market participants.

Here again, a relatively long disclosure lag (e.g a couple of years) is not very detrimental to the benefits of transparency, but it is important to get access to data with the same granularity as the regulator to replicate his/her information set.

\section{c. Complementarity with the internal reporting system of financial institutions}

The standardization of back-office booking of positions among banks and other financial institutions creates a mutually beneficial situation for both regulators and financial institutions. On the one hand, it makes regulation more efficient: reports to regulators can be directly fed by internal risk-management systems. Also, highly granular (position level) reports might be important to accelerate the standardization of new products between banks and making regulators quickly aware of the emergence of such new products. The advantage of forcing the adoption of a common asset classification is to force banks to improve backoffice and risk-management and help coordination among them.

On the other hand, standardization of back office booking also makes internal risk management systems more efficient, which in turn elicits cooperation from the financial industry. A good example is the case of transaction identifiers. In its willingness to create a reporting standard, the Office of Financial Research seeks to impose a « Legal Entity Identifier », a detailed identifying number for each financial transaction, including derivatives. The gains of doing so for the financial industry are important. First, having common identifiers makes settlement easier, which lowers back-office costs. Second, it lowers the cost of mergers, as it becomes easier to integrate different risk management systems into a single one. This made the industry coopoerative, in particular big entities who had grown through successive acquisitions.

For this positive coordination effect of data disclosure to take place, public disclosure is in theory not needed (it is enough that regulators get the information). However, public data can help private actors identifying crowded trades and staying away from them. This argument might be reversed in the presence of bailout expectations, as financial institutions might then have collective incentives to load on similar risks (see e.g. Fahri-Tirole (2010)). For disaggregate data to be informative about counterparty risk, it is important for them to be specific about the exact reporting entity, e.g. separate out assets for which the bank is liable and assets for which banks are not, which suggests aiming for relatively fine granularity. Note that such feedback into risk-management needs t take place in real time. It follows that in

\footnotetext{
${ }^{6}$ Several commentators (e.g. Johnson (2010)) have argued that regulatory capture of public agencies might have been a driving force behind the financial crisis, resulting in a lax regulatory environment placing faith in "selfregulation” via risk models internal to banks.
} 
order to induce such private risk-management effects, short lags are more important than when the purpose of public data release is the use by the academic community.

\section{Conclusion:}

While this paper focuses on the finance industry, there are general lessons that can be drawn from our analysis for other areas of regulation (such as environmental and medical data). After reviewing the potential costs of public disclosure of financial data, we have shown how they can be mitigated by the choice of long disclosure lags and coarser levels of granularity (i.e. more aggregate data). In reviewing the gains from access to public data, based on observing the use of already available public data, we emphasize the fact that long lags of disclosure (such as a couple of years) might not be a major impediment to the production of relevant contributions by academic researchers but might negatively impact the feedback into private risk-management. However, the relevance of academic contributions is more likely to be impacted by the choice of granularity of the data. In particular aggregate data seem more vulnerable to obfuscation by private actors and possibly by regulators themselves. 



\section{References}

Acharya Viral V., Philipp Schnabl, and Gustavo Suarez, 2011, "Securitization Without Risk Transfer", mimeo NYU Stern

Amador, Manuel, and Weill, Pierre-Olivier, "Learning from Prices: Public Communication and Welfare", Journal of Political Economy. 118(5), pp 866-907.

Angeletos, George-Maria, and Pavan, Alessandro, 2004, "Transparency of Information and Coordination in Economies with Investment Complementarities", American Economic Review, 94(1), pp 91-98.

Ashcraft, Adam and Til Schuermann, 2008, "Understanding the Securitization of the Subprime Mortgage Credit”, Federal Reserve Bank of New York staff reports.

Baker, Andrew, 2010, "Restraining regulatory capture? Anglo-America, crisis politics and trajectories of change in global financial governance", International Affairs, 86(3), pp 647663

Benabou, Roland, 2010, "Groupthink", Princeton working paper

Benmelech, Efraïm, and Dlugoszb, Jennifer, 2009, “The Alchemy of CDO Credit Ratings.” Journal of Monetary Economics, 56(5) pp 617-634.

Boldrin, Michele, and Levine, David, 2007, "Against Intellectual Monopoly", UCLA manuscript, available at http://www.dklevine.com/general/intellectual/against.htm Bessembinder, Hendrik, and Maxwell, William, "Transparency and the Corporate Bond Market", Journal of Economic Perspectives, 22(2), pp 217-234

Brunnermeier, Markus, and Pedersen, Lasse, 2005, "Predatory Trading", The Journal of Finance, Vol 60, pp 1825-1863.

Brunnermeier, Markus, 2009. “Deciphering the Liquidity and Credit Crunch of 2007-08”, Journal of Economic Perspectives, 23(1), 77-100.

Carhart, Mark, Ron Kaniel, and Adam Reed, 2002, "Leaning for the Tape: Evidence of Gaming Behavior in Equity Mutual Funds", Journal of Finance, 57(2), 661-693.

Cheng, Kirilenko and Xiong, 2011, "Commodity Index Traders", this volume

Coval, Joshua, and Stafford, Erik, 2007, "Asset fire sales (and purchases) in equity markets, Journal of Financial Economics, 86(2), pp 479-512.

Dang, Gorton, and Holmström, 2010, "Opacity and the Optimality of Debt for Liquidity Provision", working paper.

Edwards, Amy, Harris, Lawrence, and Piwowar, Michael, 2007, "Corporate Bond Market Transaction Costs and Transparency", Journal of Finance, 62(3), pp. 1421-1451.

Gomes, Armando, Gorton, Gary, and Madureira, Leonardo, 2007, "SEC Regulation Fair Disclosure, Information, and the Cost of Capital", Journal of Corporate Finance, 13(2-3), pp. 300-334.

Goldstein, Michael, Edith Hotchkiss, and Erik Sirri, 2007, "Transparency and liquidity: A controlled experiment on corporate bonds", Review of Financial Studies, 20(2), pp 235-273.

Graham,, John, Harvey, Campbell and Rajgopalc, Shiva, 2005, "The economic implications of corporate financial reporting", Journal of Accounting and Economics, 40, pp 3-73.

Greenwood, Robin and Thesmar, David, 2011, "Stock Price Fragility", forthcoming Journal of Financial Economics

Heron Randall A. and Erik Lie, 2007, "Does backdating explain the stock price pattern around executive stock option grants?", Journal of Financial Economics, 83, pp 271-295.

Heron Randall A. and Erik Lie, 2009, "What Fraction of Stock Option Grants to Top Executives Have Been Backdated or Manipulated?", Management Science, 55(4), 513-525. 
Holmström, Bengt, 2008, "Discussion of 'The Panic of 2007,' by Gary Gorton,“ in Maintaining Stability in a Changing Financial System, Proceedings of the Jackson Hole Conference, Federal Reserve Bank of Kansas City.

Janis, Irving, 1982, "Groupthink", Houghton Mifflin Company.

Johnson, Simon, "The Quiet Coup", The Atlantic, 2009.

Leuz, Christian, and Wysocki, Peter, 2008, "Economic Consequences of Financial Reporting and Disclosure Regulation: A Review and Suggestions for Future Research", working paper. Morris, Stephen and Shin, Hyun Song, 2002, "Social Value of Public Information.” American Economic Review, 92(5), pp. 1521-34.

Morris, Stephen, and Shin, Hyun Song, 2007, "Optimal Communication", Journal of the European Economic Association, 5(2-3), pp 594-602.

Pagano, Marco, and Volpin, Paolo, 2010, "Securitization, Disclosure and Liquidity", working paper.

Philippon, Thomas, and Reschef, Ariel, "Wages and Human Capital in the U.S. Financial Industry: 1909-2006", working paper NYU

Stigler, Georges, 1971, "The Theory of Economic Regulation", The Bell Journal of Economics, 2(1), pp 3-21.

Williams, Heidi, 2010, "Intellectual property rights and innovation: Evidence from the human genome", NBER Working paper 16213.

Zingales, Luigi, 2009, "The Future of Securities Regulation", Journal of Accounting Research, 47(2), pp 391-426. 